\title{
The Quality of Palliative Care from the Perspectives of the Elderly with Cancer at Firoozgar Hospital in 2019: A Cross-sectional Study
}

\author{
Farzaneh Farzadnia $^{1}$, Farideh Bastani $^{2}$, Hamid Haghani ${ }^{3}$
}

\begin{abstract}
Background \& Aims: Along with the growth of the aging population, there are several challenges for this population group as well as for caregivers and health policymakers. One of the most important challenges is the increase in care needs due to the increased suffering of the elderly from chronic and malignant diseases and disabilities. Therefore, due to the high prevalence of cancer and also the growth of the aging population, palliative care appears to be one of the important priorities of the health system. Palliative care has been identified as an important and ongoing part of cancer care. Palliative care is an approach that improves the quality of life of the patient and his family in the face of problems related to life-limiting diseases by preventing the patient's suffering and improving the patient's symptoms and other physical, mental, spiritual, and social problems. In fact, palliative care alleviates the disease-related pain and its effects on the patient and her family from the diagnosis of the disease to the control of pain and other symptoms. Studies have shown that there is a significant relationship between palliative care received and the quality of life in patients with chronic diseases such as cancer. Quality of life is also a multidimensional concept and nurses have an important role in improving the quality of services and care by considering the physical, mental, spiritual, religious, cultural, and social aspects of the patients. Therefore, it is necessary to first investigate the existing conditions and the quality of palliative care in the health centers and then take effective measures to improve them. Therefore, this study was conducted to determine the quality of palliative care from the perspectives of the elderly with cancer admitted to Firoozgar Educational and Medical Center in 2019.

Materials \& Methods: This was a cross-sectional study. A total of 123 elderly patients with cancer admitted to Firoozgar Hospital in 2019 (November to January 2019) were selected through continuous sampling procedure. Inclusion criteria were informed consent to participate in the study, no cognitive impairment (a minimum score of 7 out of 10 based on AMT test) in the elderly, the ability to communicate and answer the items of the questionnaire, no known mental illness (based on the patient's medical record), confirmed cancer (according to the medical diagnosis and medical record). The exclusion criteria were no consent to participate in the study, noncooperation in each stage of completing the questionnaire (AMT, demographic form, palliative care quality tools). Data collection tools included the short-form anxiety management training (AMT) to analyze the elderlies' mental health status and cognitive system, demographic form, and quality end of life questionnaire (QEOLC-10) which were completed through face-to-face interviews with the samples. The palliative care quality questionnaire assesses the quality of palliative care provided from the perspectives of patients with chronic diseases. This questionnaire includes 10 items with different dimensions of staff communication skills, patient-centered care system, symptom reduction management, staff emotional skills, and care based on patient values which are rated on an 11-point scale (range: 0-10). Data were analyzed using descriptive and inferential statistics such as independent t-test and ANOVA using SPSS Software version 16 at the significance level of $\mathrm{P} \leq 0.05$.

Results: The mean age of the elderlies was $65.55 \pm 4.12$ years. The highest frequency was related to the age group of 60-64 years, which shows that the subjects were classified as young-old. Among them, $76(61.8 \%)$ cases were male and $47(38.2 \%)$ were female. Almost all samples in these studies were married (95.9\%), retired and

\footnotetext{
1. MS Geriatric Nursing, School of Nursing and Midwifery, Iran University of Medical Sciences, Tehran, Iran 2. Department of Community Health Nursing and Geriatric Nursing, School of Nursing and Midwifery, Iran University of Medical Sciences, Tehran, Iran. $\quad$ (Corresponding author) Tel: 02143651820 Email: bastani.f@iums.ac.ir 3. Department of Biostatistics, School of Health, Iran University of Medical Sciences, Tehran, Iran
} 
unemployed elderly had the highest frequency with $(47.2 \%)$ and $(41.5 \%)$, respectively. More than half of the study samples, about (56.9\%), had a history of hospitalization, among which $(47.1 \%)$ declared that they were hospitalized for one to two weeks and (48\%) of the elderly were suffering from gastrointestinal cancer, which was more common than other types of cancer. In this study, the quality of palliative care in various dimensions (patientcentered care system, personnel communication skills, symptom reduction management, personnel emotional skills, patient values) was at the desired level. (54.5\%) of the elderly reported the quality of palliative care to be desirable. The mean and standard deviation of palliative care quality was $65.55 \pm 4.12$. In all dimensions of quality of care, the two variables of the current hospitalization period $(\mathrm{P}=0.012)$ and nursing skills $(\mathrm{P}<0.001)$ had the most statistically significant relationship with the quality of palliative care. The quality of palliative care in pain management had a statistically significant relationship with gender $(\mathrm{p}=0.047)$, current hospitalization period $(\mathrm{P}=0.015)$, and nurses' skills $(\mathrm{P}<0.001)$, which was significantly higher in men than women, and had the highest frequency during 3-4 days of hospitalization, and nursing skills had a significant role in all the aspects.

Conclusion: In general, the results of this study showed that relief from physical, psychosocial, social, and spiritual problems through palliative care is possible for more than $90 \%$ of patients at the advanced stages of cancer. Palliative care to treat and alleviate the cancer-related symptoms and improve the quality of life of patients and their families can help people live more comfortably. It is especially true in places where there is a large number of patients with advanced cancer and there is little chance of treatment. In this study, the quality of palliative care from the perspective of the studied elderly was rated as desired, which is one of the reasons for providing such services in the special palliative care ward of Firoozgar Medical Center with experienced and trained caregivers. However, the main problem of the nursing system in Iran regarding palliative care for patients with cancer is that this type of care does not have a specific framework for nurses and is not seriously included in the formal curriculum.

Keywords: Palliative care, Cancer, The Elderly, Geriatric Nursing

\section{Conflict of Interest: No}

How to Cite: Farzadnia F, Bastani F, Haghani H. The Quality of Palliative Care from the Perspectives of the Elderly with Cancer at Firoozgar Hospital in 2019: A Cross-sectional Study. Iran Journal of Nursing. 2021; 34(130):59-72.

Received: 15 March 2021

Accepted: 16 Jun 2021 


\title{
كيفيت مراقبتهاى تسكينى از ديدكاه سالمندان مبتلا به سرطان بسترى در بيمار ستان فيروزكر

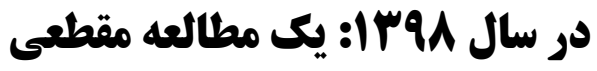

\author{
فرزانه فرزاد نيا'، فريده باستانى '، حميد حقانى"
}

\begin{abstract}
جكيده

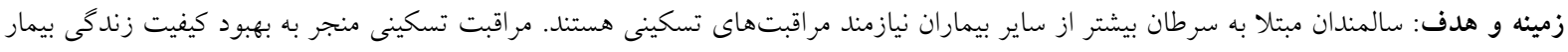

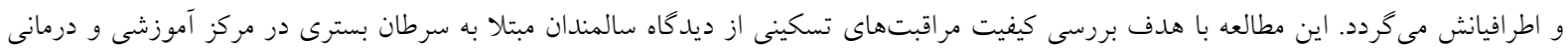
فيروزكر سال 1وسبا انجام شده است.

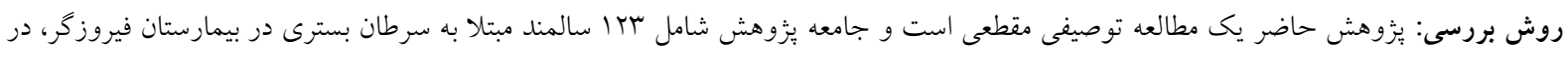

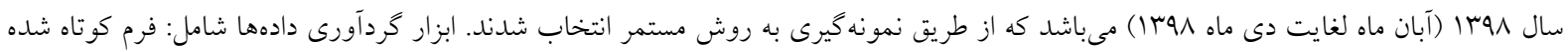

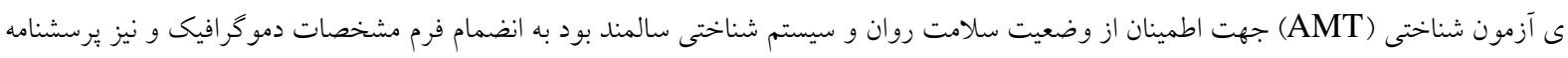

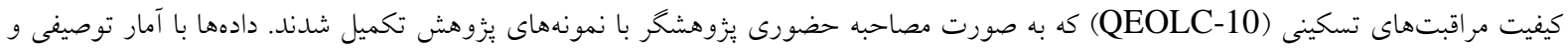

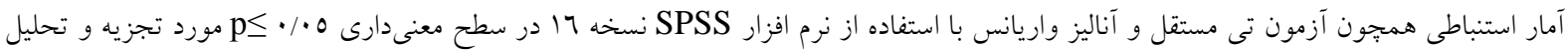
قرار خر فتند.
\end{abstract}

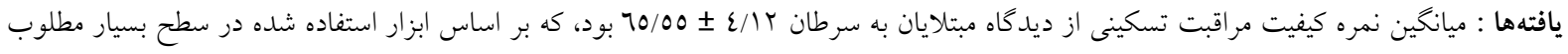

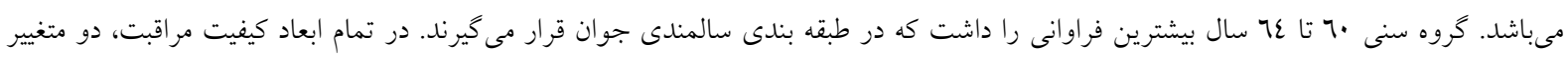

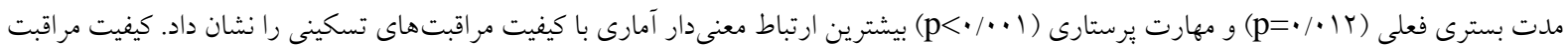

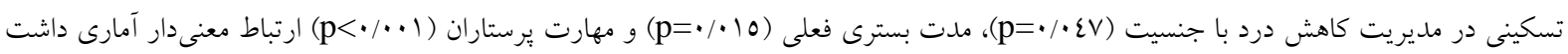

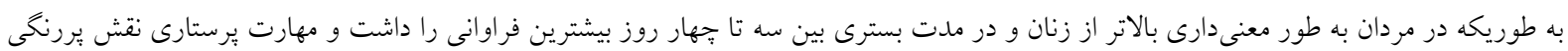
در تمام ابعاد داشت.

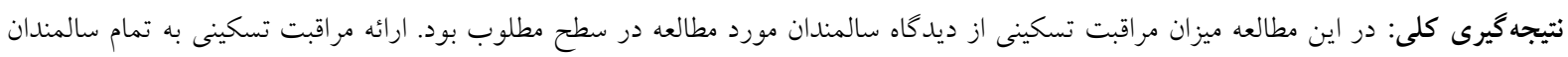
مبتلا به سرطان امرى ضرورى است و برستاران بالينى نقش مهمى در ارتقاء كيفيت مراقبتهاى تسكينى بر عهده دارند.

كليد وازهها: سالمند، سرطان، مراقبت تسكينى، برستار سالمند تعارض منافع: وجود ندارد. تاريخ دريافت:

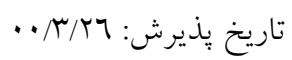

(نويسنده مسئول)

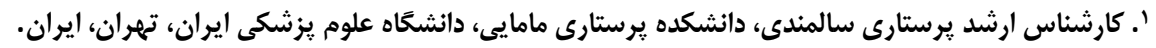

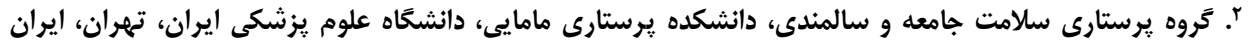

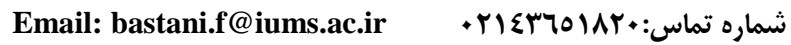

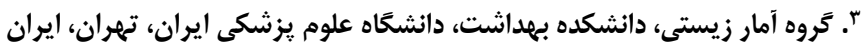


تشخيص داده شده مبتلا به سرطان و •V درصد مرك ناشى

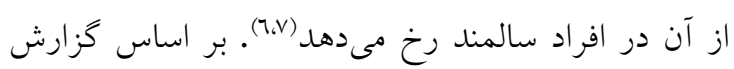

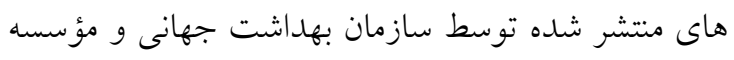

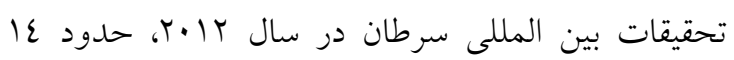

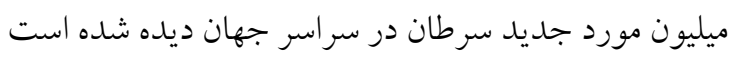

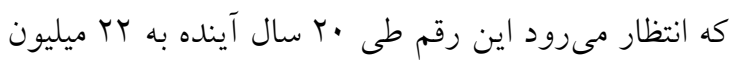

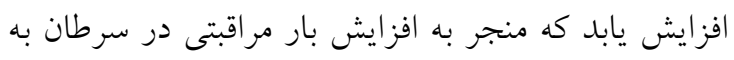

$$
\text { صورت جهانى مى شود (1). }
$$

بنابراين با توجه به شيوع زياد سرطان و همجنين رود رشد فزاينده بِديده سالمندى، مراقبتهاى تسكينى به عنوان يكى از اولويتهاى مهم نظام سلامت نمايان مىشود.

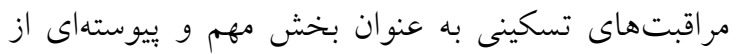

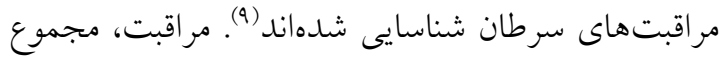
مداخلاتى است كه با هدف تأمين سلامت انسان در تمام

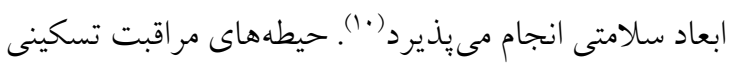

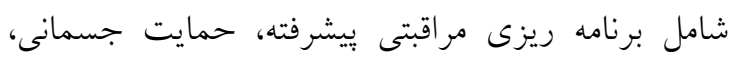

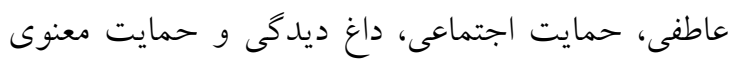

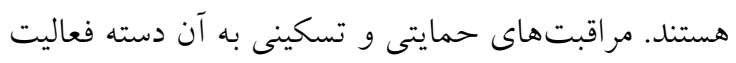

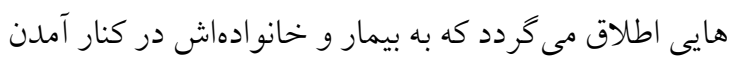

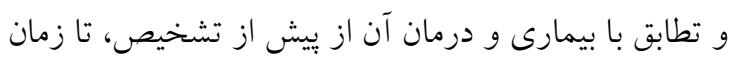

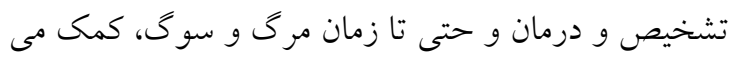

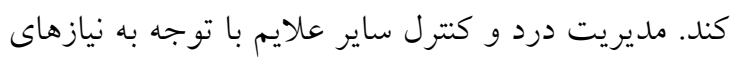
عاطفى، روانى و اجتماعى مددجويان و خانو اده مىباشد. از اين رو، مراقبت تسكينى تنها در تسكين درد بيمار خلاصه ماصف نمىشود، بلكه زمينه روانى را براى بذيرش مرى در در بيمار

$$
\text { تسهيل مى نمايد (1'). }
$$
مراقبت تسكينى، رويكردى است كه كيفيت زندكى بيمار و خانواده وى را در مواجهه با مشكلات مربوط به بيمارى

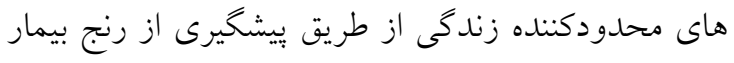
و بهبود علائم و ساير مشكلات جسمى، روانى، معنوى و

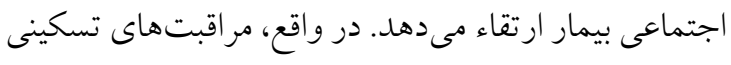
از لحظه تشخيص بيمارى، تا كنترل درد و علائم ديخر، رنج ناشى از بيمارى و عوارض حاصل از آن را در بيمار و و خانوادهاش تسكين مى دهد (r).

\section{مقدمه}

آمارها نشان مى دهد تعداد افر اد سالمند در دنيا سير صعودى

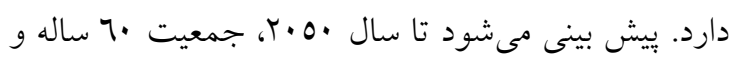

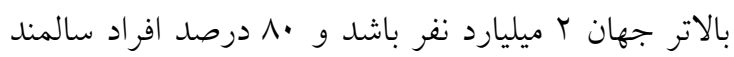
در كشورهاى كم درآمد و متوسط زندكى خواهند كرد (1).

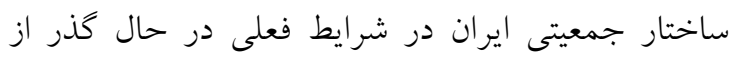
جمعيت جوان به ميانسال است و به زودى به كشورهاى بال

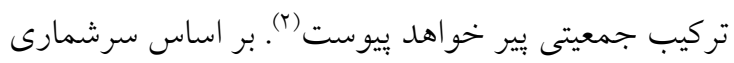

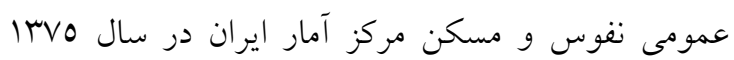

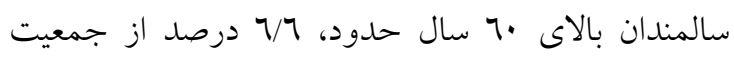

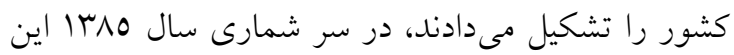

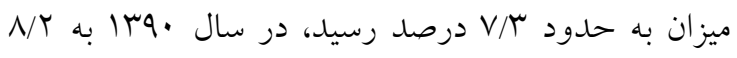
درصد و در سال 90با تعداد سالمندان حدود V/2 ميليون

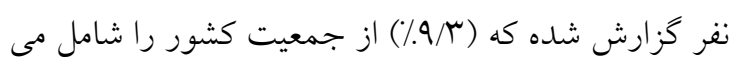
شوند (r). همشام با افزايش جمعيت سالمندان، جالشهاى مهاى متعددى هم براى اين گروه جمعيتى و هم براى مراقبان و سياست

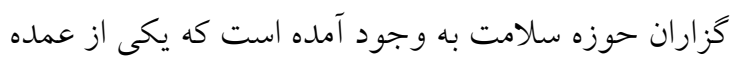

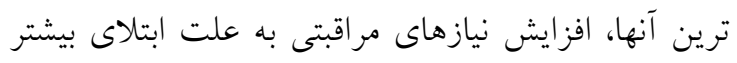

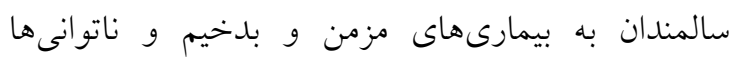

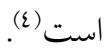

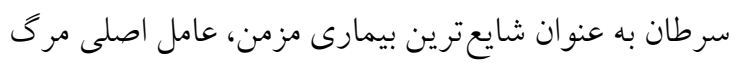

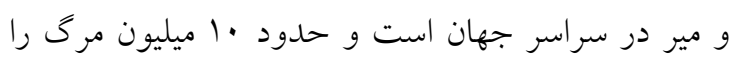

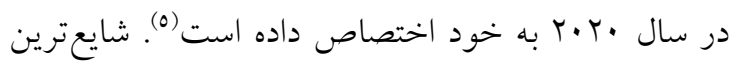

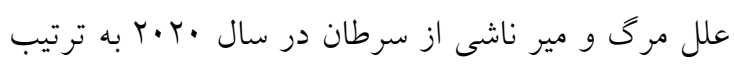
شامل سرطان ريه، سرطان روده بزرى و راست رئ روده،

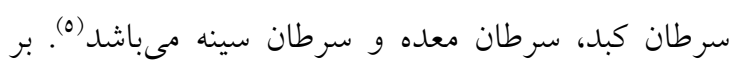

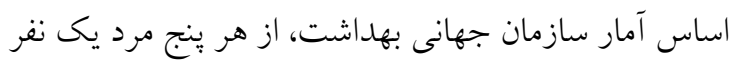
و از هر شش زن يك زن در سراسر جهان به سرطان مبتلا

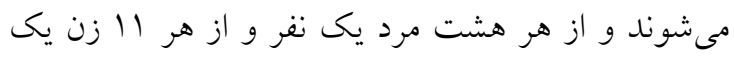
نفر بر اثر اين بيمارى مى ميرند (1).

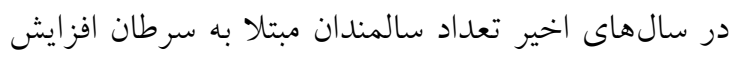

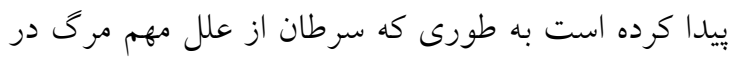
اين گروه سنى محسوب مىشود. تقريباً •7 درصد موارد 
كيفيت مراقبتها و آرامش و رضايتمندى بيماران سالمند بسترى در بخش مراقبت تسكينى و انكولوزى بيمارستان فيروزگر (به عنوان مشتريان نظام سلامت) قرار گيرد.

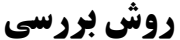

اين مطالعه مقطعى از نوع توصيفى بود كه از آذرماه تا بهمن

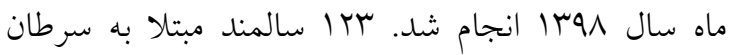
بسترى در بخش مراقبت تسكينى مركز آموزشى درمانى مانى

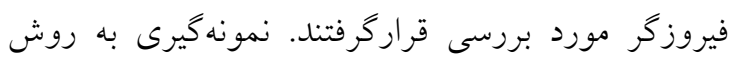

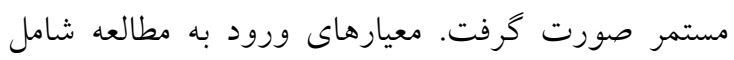

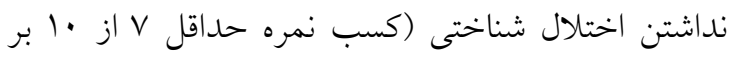
مبناى تست Abbreviated Mental Test) AMT در سالمند مورد مطالعه، توان برقرارى ارتباط و ياسخ دهى لهي

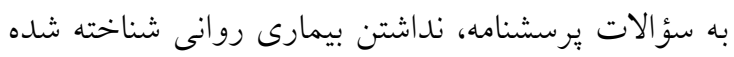

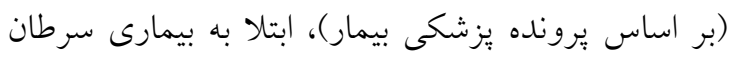
تثبيت شده (طبق تشخيص يزشكى و ثبت در برونده) بود.

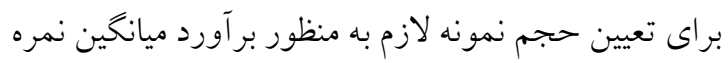

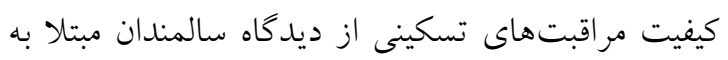

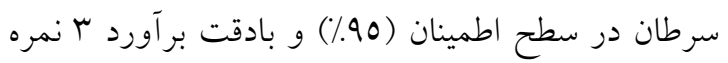

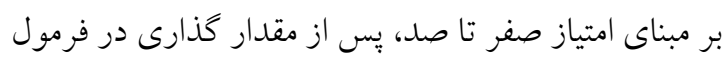

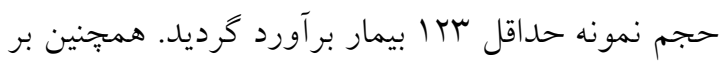
IV اساس نمره كيفيت مراقبت برمبناى صد انحر اف معيار

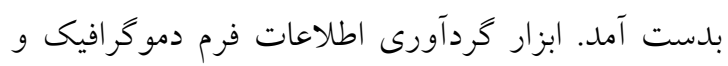
يرسشنامه كيفيت مراقبتهاى تسكينى بود. فرم اطلاعات

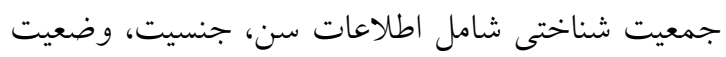

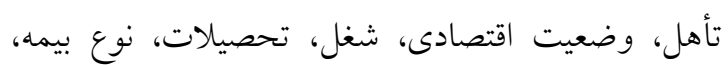
سابقه بسترى شدن، طول مدت بسترى، بيمارى همراه،

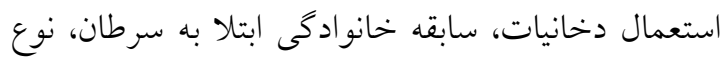

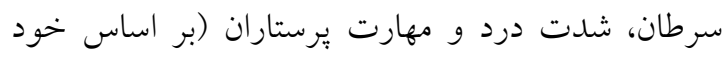

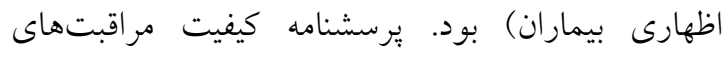

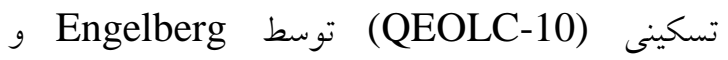

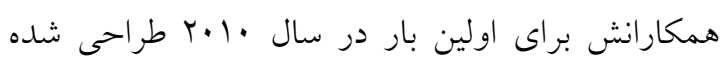

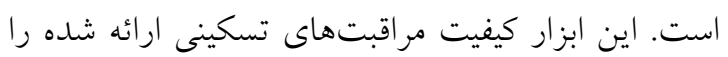

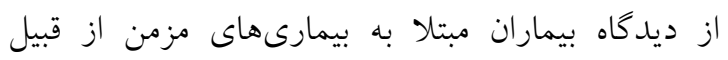

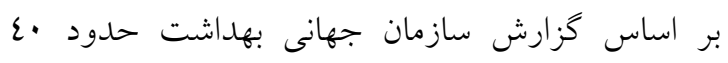
ميليون نفر در دنيا نيازمند مراقبتهاى تسكينى هستند.

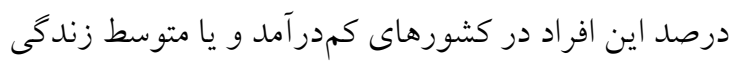

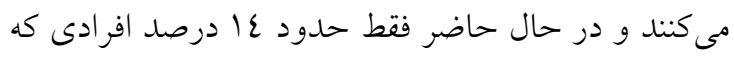

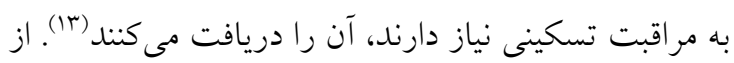

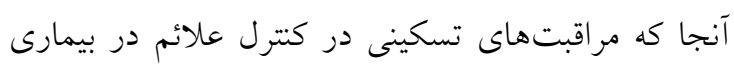

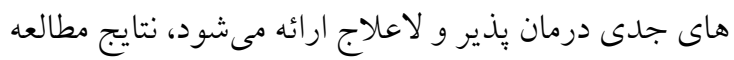

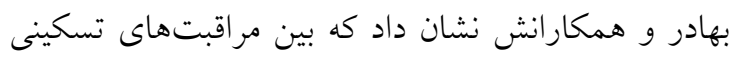

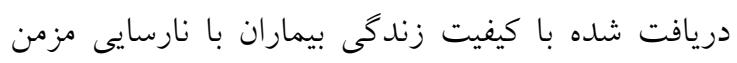

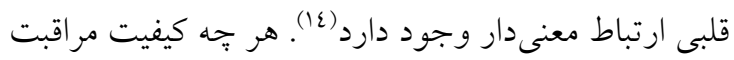
هاى برستارى جهت بيماران در طول مدت بسترى در

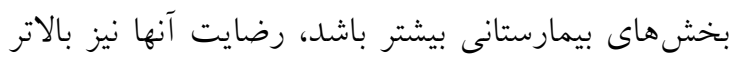

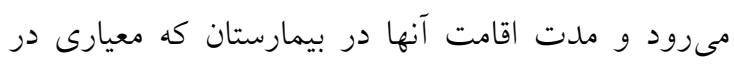

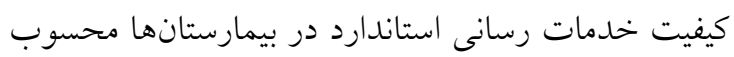
مىشود نيز كمتر مىشود. هر خهه ارتباط مطلوبترى بين

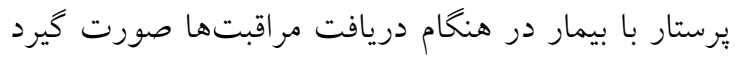

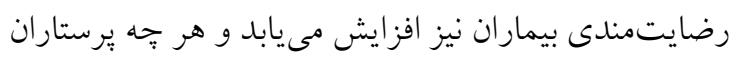

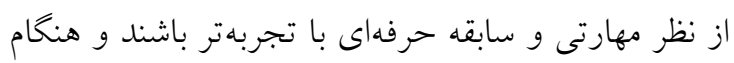

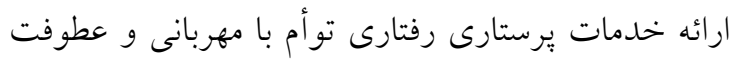

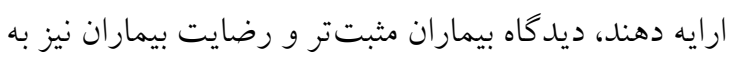

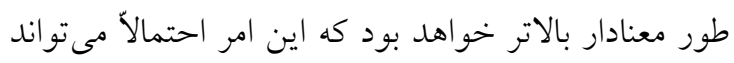
در سرعت بهبودى بيمار كمك شايانى بنمايد (10).

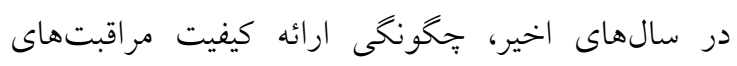

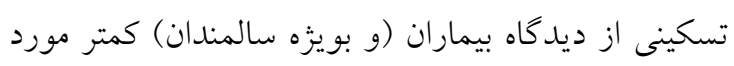

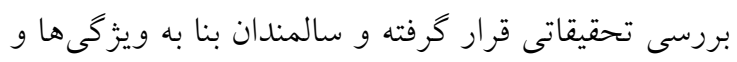

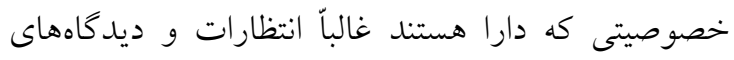

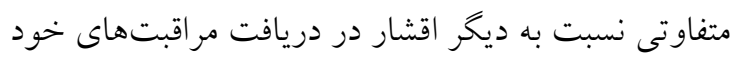

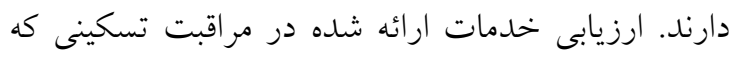
اطلاعات پِايهاى براى نياز سنجى و ارزيابى مديران و

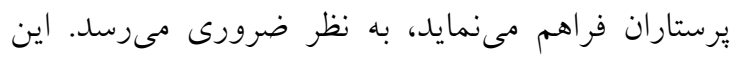
مطالعه با هدف تعيين كيفيت مر اقبتهاى تسكينى از ديدكاه

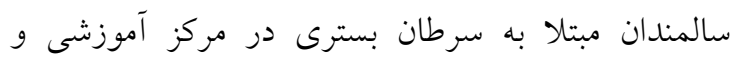
درمانى فيروزگر سال يوسا انجام شد تا مبنايى براى انجام

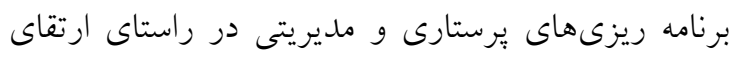


توسط بزوهشخر تكميل شد. جهت يُشخيرى از خستخى و كسل شدن سالمند در فواصل تكميل فرم مشخصات

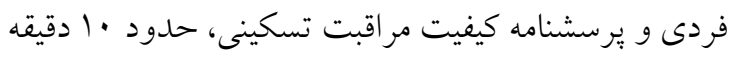
فرصت اضافى استراحت فراهم شد تأ تكميل ابزار

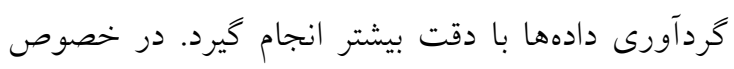

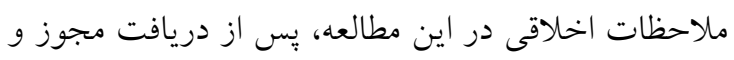
تأييديه كميته اخلاق (IR.IUMS.REC.1398.533)

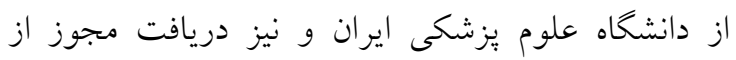

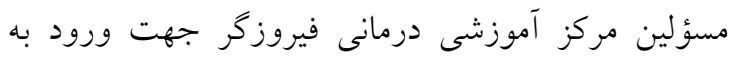

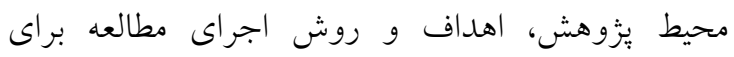
واحدهاى يزّوهش توضيح داده شد و به آنها اطمينان داده

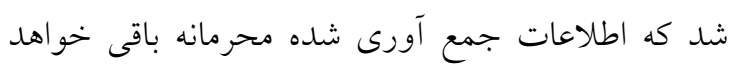
ماند. نتايج مطالعه نيز در صورت تمايل در اختيار مسئولين

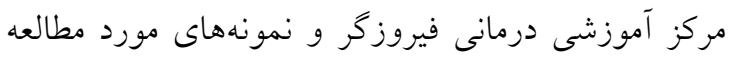
قرار داده مىشود. بعد از جمع آورى دادهها و ورود آنها به نرم افزار نسخه 17 در اين مطالعه، از آمار توصيفى در قالب جدود أندول

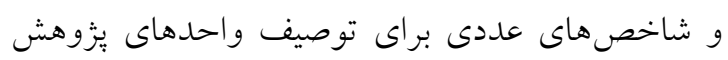

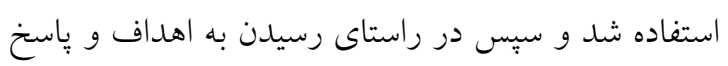

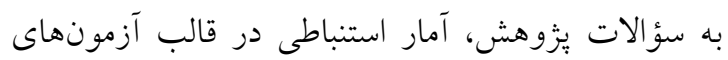

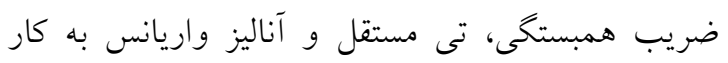
كرفته شد.

\section{بافتهها}

بررسى مشخصات دموكرافيك نمونهها نشان داد ميانخين

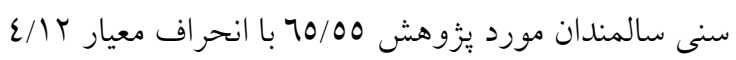

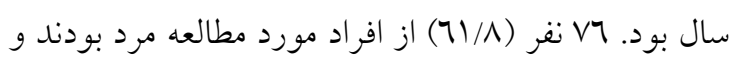
بيشتر واحدهاى مورد بزوهش يعنى 90/9 درصد متأهل

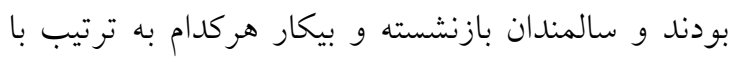
EV/T تحصيلات دييلم با T/T درصد بيشترين سطح تحصيلى بين ساير سطوح تحصيلى بود (جدول شماره ().
سرطان، سندرم نقص ايمنى اكتسابى و بيمارى مزمن

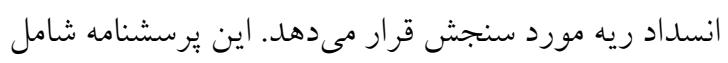

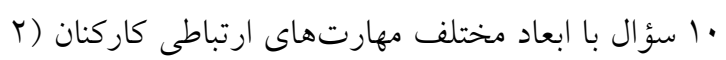

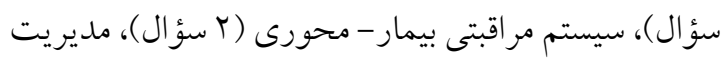

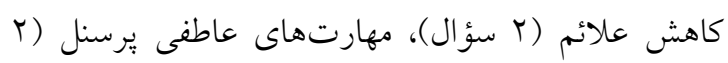

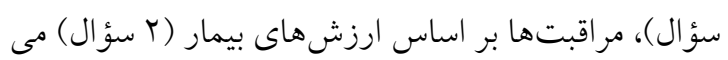

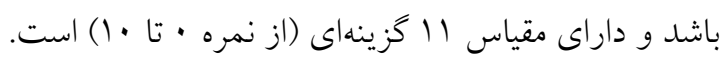

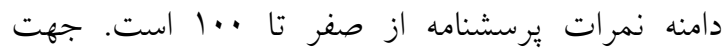
توصيف ديدكاههاى نمونههاى يزوهش، كيفيت مراقبت

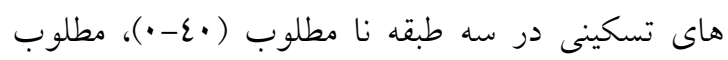

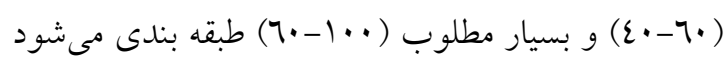
و در كل كسب نمره بيشتر نشاندهنده كيفيت مراقبت

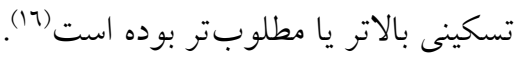

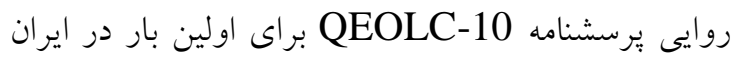

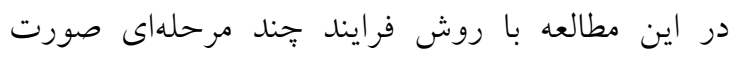
كرفت. جهت روايى و استفاده از برسشنامه انخليسى فرايند

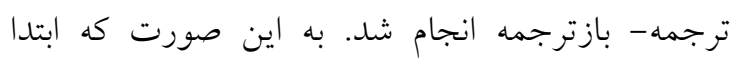

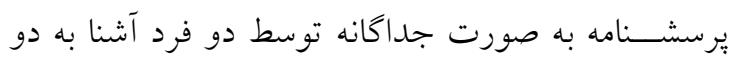

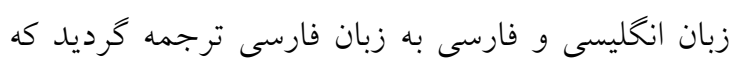

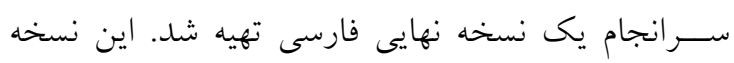

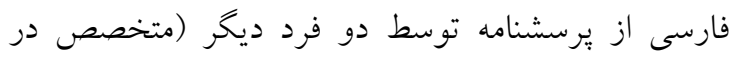

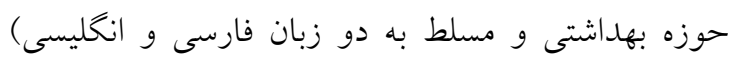

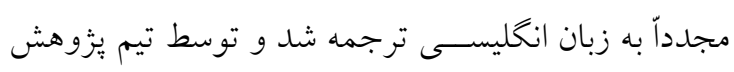

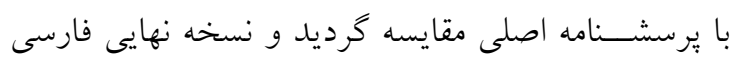

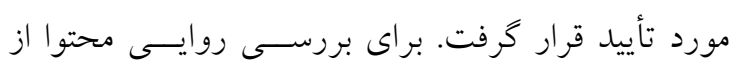
سه هيأت علمى به عنوان بِانل خبر كان (Expert Panel)

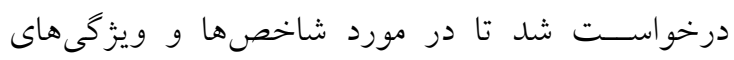

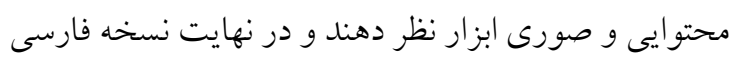

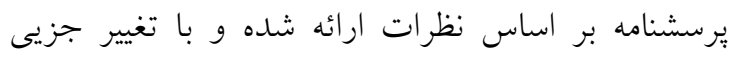
اصلاح نهايى شده و مورد استفاده قرار گرفت. بايايى ابزار

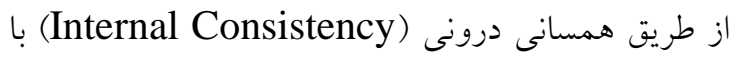

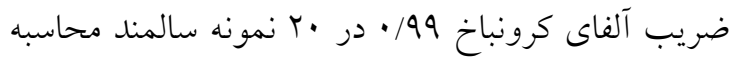
كرديد. در اين يُوهش تمام يرسشنامهها از طريق مصاحبه 
جدول شماره ا: توزيع فراوانى مشخصات فردى سالمندان مبتلا به سرطان بسترى در مركز آموزشى و درمانى فيروزتر

\begin{tabular}{|c|c|c|}
\hline \multirow{2}{*}{ فراوانى (درصد) } & \multicolumn{2}{|c|}{ مشخصات فردى } \\
\hline & $7 \cdot-7 \varepsilon$ & \\
\hline$(\varepsilon r / r)$ or & $70-7$. & سن (سال) \\
\hline$(\mid r / 0) 10$ & ل vو بالاتر & \\
\hline$(71 / \Lambda) \vee 7$ & مرد & جنسيت \\
\hline$(r \wedge / Y) \varepsilon V$ & زن - ت ن & \\
\hline$(1 / 7) Y$ & مجرد & \\
\hline$(90 / 9) 111$ & متأهل & وضعيت تأهل \\
\hline$(\cdot / \Lambda) 1$ & بيوه & \\
\hline$(1 / 7) r$ & مطلقه & \\
\hline$(11 / \varepsilon) 1 \varepsilon$ & شاغل & \\
\hline$(\varepsilon 1 / 0) 01$ & بيكار & وضعيت شغلى \\
\hline$(\varepsilon V / r) 01$ & بازنشسته & \\
\hline$(r Y / \Lambda) \nvdash \Lambda$ & بيسواد بيسو & \\
\hline$(10 / 2) 19$ & ابتدايى & \\
\hline$(9 / \Lambda) i r$ & 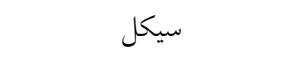 & تحصيلات \\
\hline$(T r / T) r q$ & دييلم & \\
\hline$(7 / 0) \wedge$ & كاردانى & \\
\hline (Ir) 17 & كارشناسى & \\
\hline$(1 / 9) 11$ & ارشد و بالاتر & \\
\hline$(V \Lambda) 97$ & دارد & وضعيت بيمه \\
\hline$(Y Y) Y V$ & 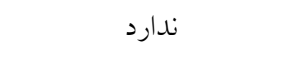 & \\
\hline$(07 / 9) V$. & دارد & سابقه بسترى \\
\hline$(\varepsilon r / 1)$ or & ن ندارد & \\
\hline$(r / 9) \pi r$ & كمتر از يك هفته & \\
\hline$\left(\sum V / 1\right) \pi$ & يك هفته تا دو هغته & مدت بسترى قبلى \\
\hline$(r \cdot) \backslash \varepsilon$ & بيشتر از دو هفته & \\
\hline$(\Gamma T / \Gamma) \vee \wedge$ & دارد & بيمارى همراه \\
\hline$(r o / T) 1 T r$ & ندارد & \\
\hline$(01 / 1) 17$ & بيمارىهاى قلبى & \\
\hline$(01 / 1) \pi r$ & غدد & نوع بيمارى زمينهاى \\
\hline$(1 \pi / \mu) 7$ & ساير بيمارىها & \\
\hline$(r Y / \Lambda) \Upsilon \Lambda$ & دارد & استعمال دخانيات \\
\hline$(V / T) 90$ & ندارد & \\
\hline$(\varepsilon r / r)$ or & دارد & مصرف دارو \\
\hline$(O V / V) \vee 1$ & ندارد & \\
\hline$(19 / r) 1$. & دارو هاى ضد انعقاد خون & \\
\hline$(T N / \Lambda) 10$ & داروهاى قلبى & نوع دارو \\
\hline$\left(r_{N / O}\right) r$. & داروهاى ديابت & \\
\hline$(1 r / 0) V$ & ساير داروها & \\
\hline
\end{tabular}


داروهاى ديابت با N/Nم درصد بيشترين فراوانى را داشت. مدت بسترى ع/qس درصد از سالمندان مورد يزوهش بين

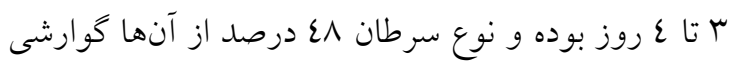
بود كه نسبت به ساير سرطانها فراوانى بيشترى داشت.

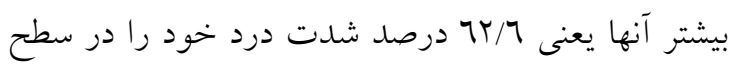
متوسط دانستند و همجنين 70 درصد مهارت برستاران را

$$
\text { در سطح متوسط ارزيابى كرده بودند. }
$$

در اين مطالعه كيفيت مراقبت تسكينى در ابعاد سيستم مراقبتى بيمار - محورى، مهارتهاى ارتباطى، مديريت كاهش درد، مهارتهاى عاطفى و مراقبتها بر اساس نرس ارزشهاى بيمار در سطح مطلوب بود (جدول شماره ؟).
مشخصات مربوط به بيمارى افراد مورد مطالعه نشان داد

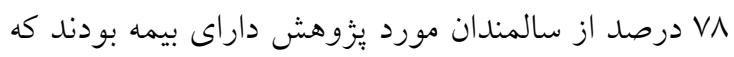
از اين ميان بيمه تأمين اجتماعى با // إ درصد بيشترين فراوانى را در بين ساير بيمهها داشت. بيش از نيمى از واحدهاى مورد يُزوهش يعنى 07/9 درصد سابقه بسترى داشتند كه از اين ميان VV// درصد مدات بسترى خود را يك تا دو هفته اعلام كرده بودند. ع/س7 درصد اعلام كرده بودند داراى بيمارى همراه نيستند و از بين سالمندانى كه اعلام كرده بودند داراى بيمارى همراه هستند بيمارى غدد

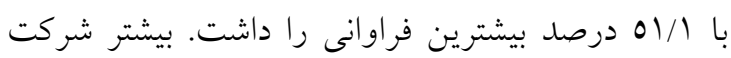
كنندكان يعنى VV/T درصد استعمال دخانيات نداشتند و א/T/T درصد مصرف دارو داشتند كه از اين ميان مصرف

جدول شماره r: كيفيت مراقبتهاى تسكينى از ديدًاه سالمندان مبتلا به سرطان در ابعاد مختلف

\begin{tabular}{|c|c|c|}
\hline ميانخين (انحر اف معيار) & سؤالات & ابعاد \\
\hline \multirow[t]{4}{*}{$(1 / 94) 0 / 29$} & - به شما، اعضاى خانو اده و دوستانتان كمك ميكنند تا اطلاعات يكسان از مراقبتهاى بهداشتى & 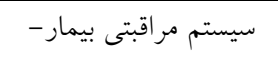 \\
\hline & 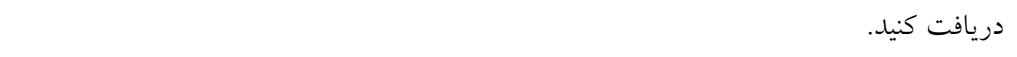 & محورى \\
\hline & - به شما اطمينان مىدهند كه قبل از وقوع مراحل دشوار (از قبيل ايست قلبى تنفسى) رها & \\
\hline & 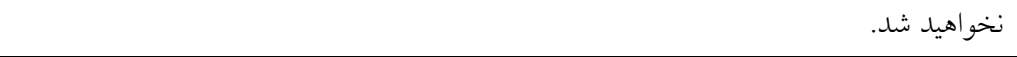 & \\
\hline \multirow[t]{2}{*}{$(1 / 9 \varepsilon) 0 / \varepsilon V$} & - -رو راست و صادقانه با شما صحبت مى كنند. & 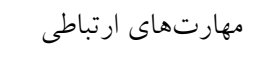 \\
\hline & - با روى گشاده و با اشتياق، با اعضاى خانو اده و دوستان شما ارتباط برقرار مى كنند & تيرسنل \\
\hline \multirow[t]{2}{*}{$(1 / 9 \varepsilon) 0 / \varepsilon q$} & - خواستههاى شما را در هنگام مديريت درد و علائم در نظر مى گيرند & مديريت كاهش علائم \\
\hline & - از مراقبتهاى مورد نياز در مراحل دشوار (از قبيل ايست قلبى تنفسى) آكاهى دارند. & \\
\hline \multirow[t]{2}{*}{$(1 / 11) 0 / 0 \varepsilon$} & - نيازهاى عاطفى شما را مورد توجه قرار مىدهند. - & مهارتهاى عاطفى برسنل \\
\hline & - كل موجوديت فرد بيمار را در نظر مى گيرند، نه اينكه صرفاً بيمارى را در نظر بخيرند. & \\
\hline \multirow[t]{2}{*}{$(1 / V \Lambda) 0 / 09$} & - - جيزهايى كه نمى دانند را مى يذيرند. & 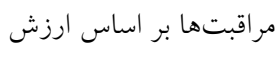 \\
\hline & - - به اعتقادات شخصى شما احترام مى گذارند. & ل ماى بيمار \\
\hline
\end{tabular}

جدول شماره س: توزيع فراوانى كيفيت مراقبت تسكينى سالمندان مبتلا به سرطان بسترى در مركز آموزشى و درمانى فيروز

\begin{tabular}{|c|c|c|}
\hline درصد & فراونى & كيفيت مراقبت تسكينى \\
\hline$I T / T$ & 10 & نامطلوب (•ع-•) \\
\hline $0 \varepsilon / 0$ & TV & مطلوب (•7-••๘) \\
\hline 每 & そ & بسيار مطلوب ( •-1-7) \\
\hline \multirow[t]{3}{*}{$1 \cdots$} & Irr & جمع كل \\
\hline & $70 / 00 \pm \varepsilon / 1 T$ & انحراف معيار 土 ميانخين \\
\hline & $7-\mathrm{VA}$ & بيشينه - كمينه \\
\hline
\end{tabular}

توزيع فراوانى كيفيت مراقبت تسكينى سالمندان مبتلا به سرطان بسترى در مركز آموزشى و درمانى فيروزكر نشان داد 0ع/0 درصد از سالمندان مورد يزوهش كيفيت مراقبت تسكينى را در سطح مطلوب دانستند و ميانخين نمره كسب

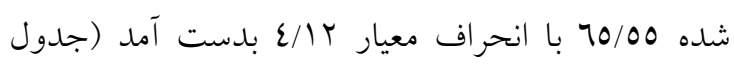

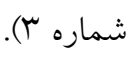


دارد. نتايج مطالعه Al-Awamreh \& Suliman در بحث و نتيجه كشور اردن نشان داد بيماران بسترى در بيمارستان از كيفيت مراقبتهاى يرستارى و دريافت خدمات بهداشتى ارائه

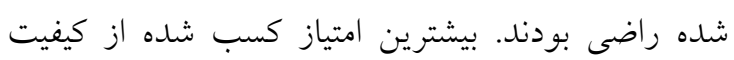

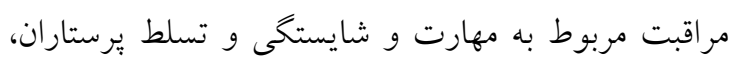

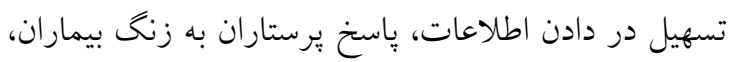

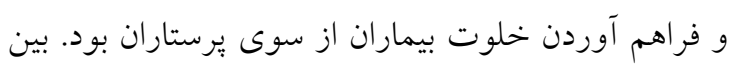

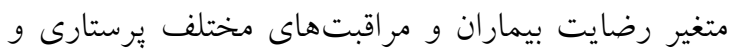

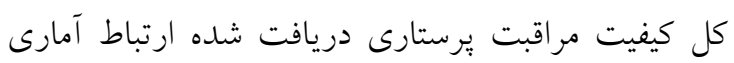

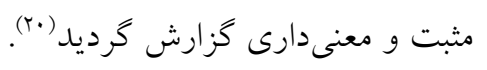

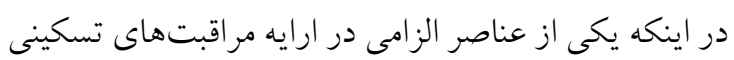

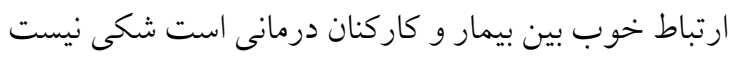
برقرارى ارتباط جزء انسانى و جدايى نايذير مراقبتها محسوب شده كه منجر به ايجاد شناخت بين برستار و بيمار

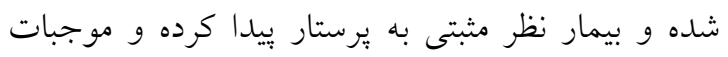

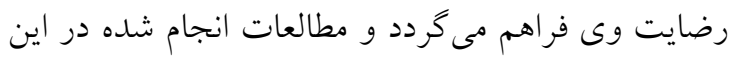

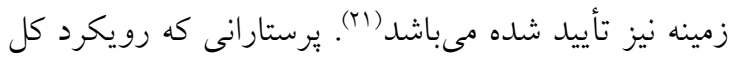

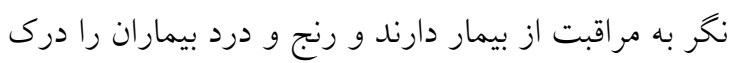

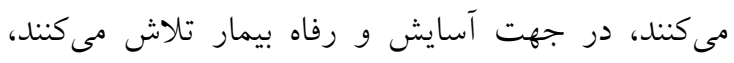

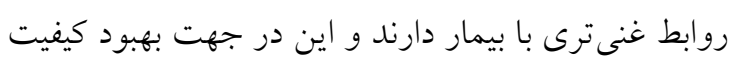

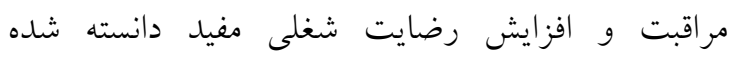

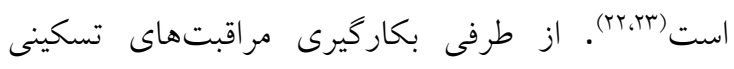
محدود به بيمارىهاى خاص نمىباشد. بطوريكه، مشاوره

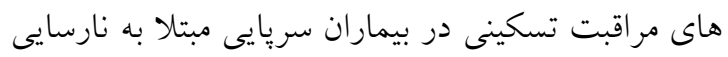

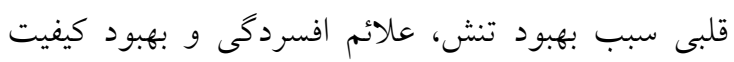

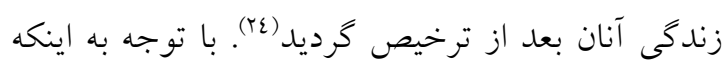

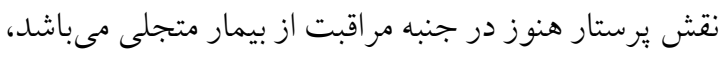

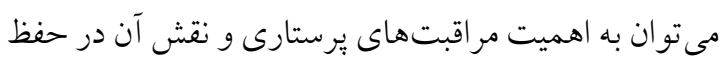
جان افراد جامعه يُى برد. يرستاران بايد در مقابل ارائه

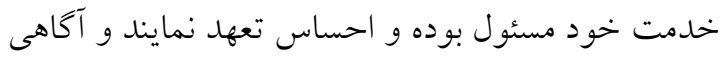
و مهارت كافى در امر مراقبت از بيمار داشته باشند كه اين خود نه تنها سبب بهبود كيفيت بلكه باعث ييشرفت شغلى

$$
\text { آنان نيز خواهد شد (r.). }
$$

به طور كلى در مطالعه حاضر كيفيت مراقبت تسكينى ديجى ديرى سالمندان مبتلا به سرطان در سطح مطلوب قرار داشت دمان. بيشتر سالمندان اين مطالعه در طبقه سالمندى جوان قرار

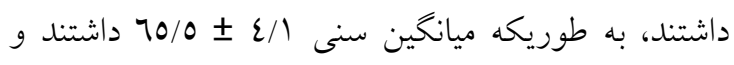
خيلى يير و فرتوت نبودند. درصد قابل توجهى از نمونهها

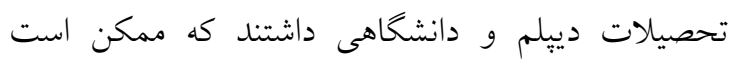
ديدكاه آنها را تحت تأثير قرار دهد. در اين مطالعه 70

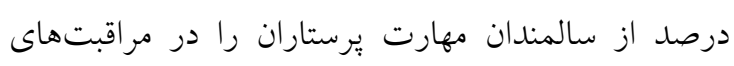

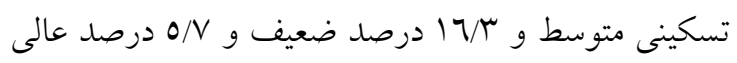
كزارش دادند. در مطالعه قلجه و همكارانش كه كيفيت

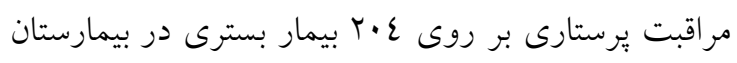

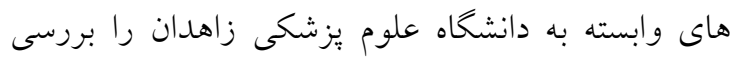

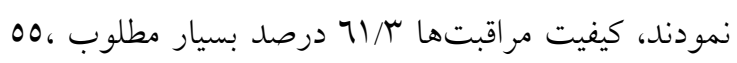

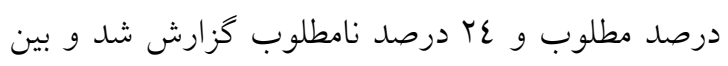
كيفيت مراقبت برستارى و رضايت بيماران ارتباط معنى دار

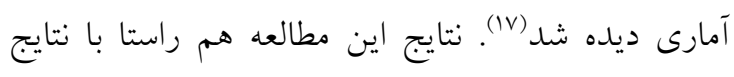
مطالعه حاضر مىباشد. مطالعه نظرى ميزان رضايت بيماران

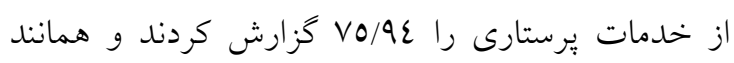
مطالعه حاضر مر اقبت در سطح مطلوب بود (1).

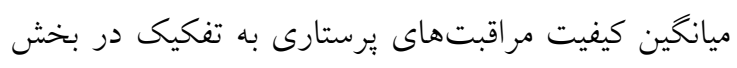

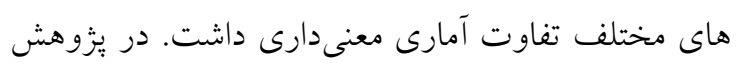

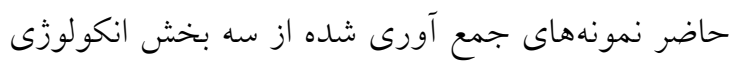

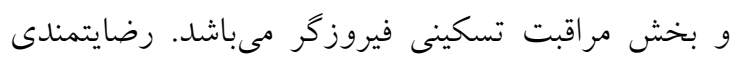

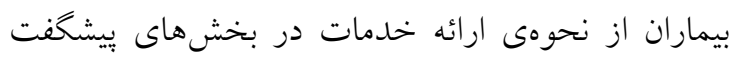

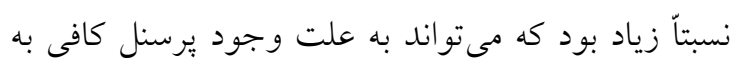

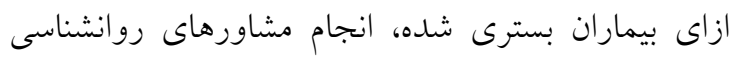

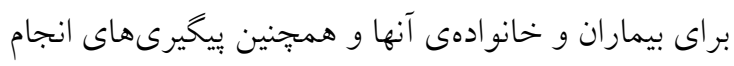

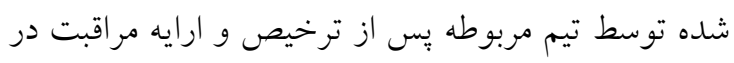

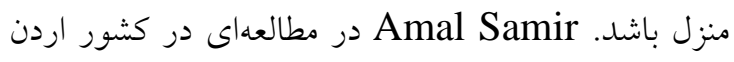

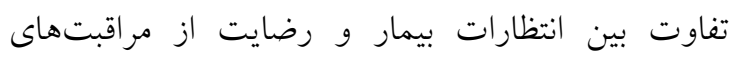

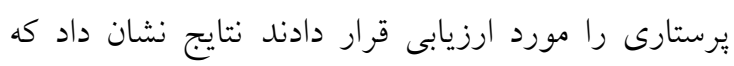

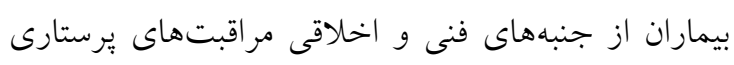

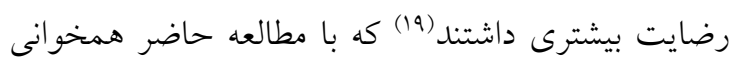


حكايت از دانش ناكافى بيماران دارد؛ به طورى كه يكى از

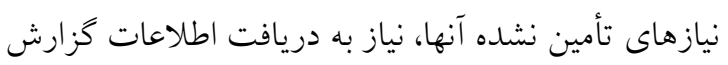

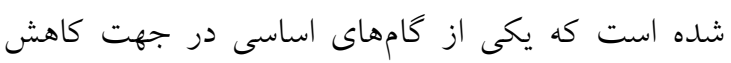

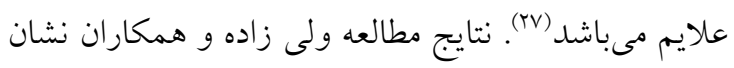

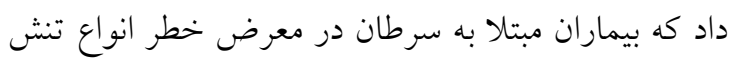

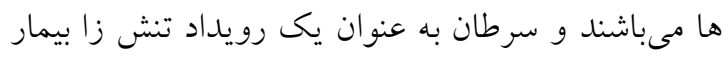

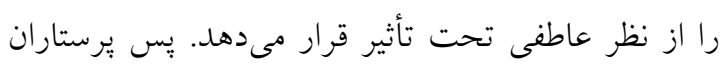

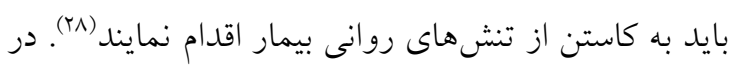

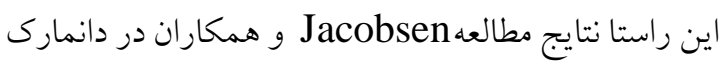
در خصوص مديريت درد در بيمار ان مبتلا به سرطان، نشان داد شدت درد در اين بيماران به ديسترس عاطفى آنان

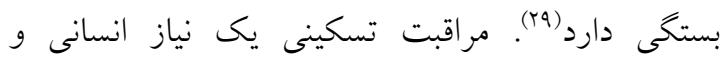

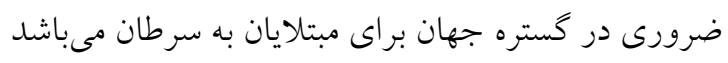
كه بخش اساسى آن كاهش علايم درد و زجر بيمار است،

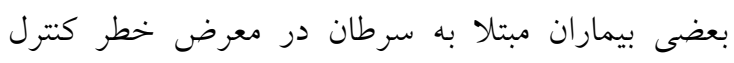

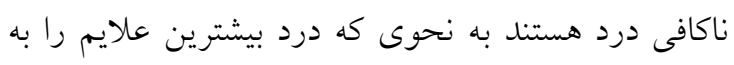

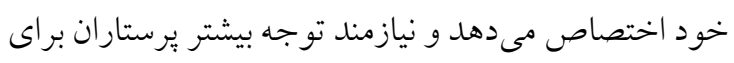

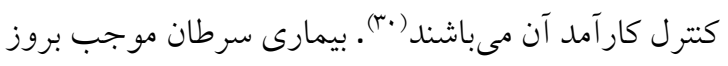
علائم جسمى و عاطفى متعددى مى گردد و حمايت كردن

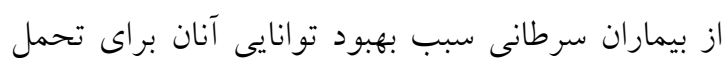

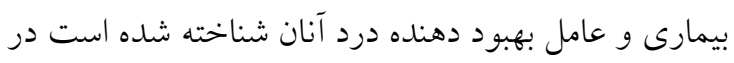

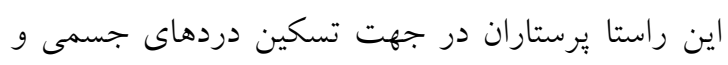

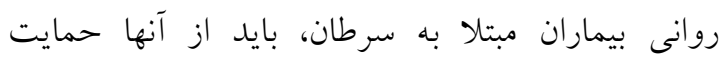
نمايند (r) نمواني بيمار در مطالعه Ferrell در امريكا مراقبت تسكينى بصورت

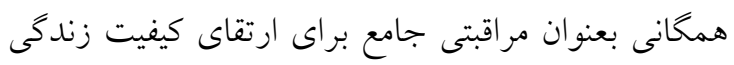

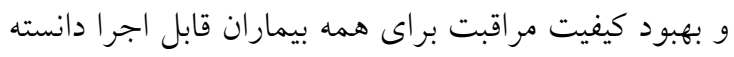

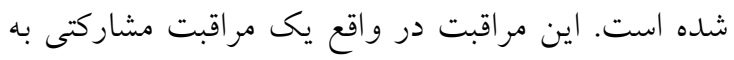

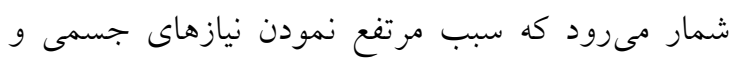

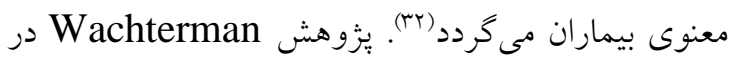

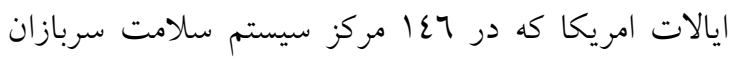
امريكايى با هدف مقايسه بِديدهها و الكوهاى مراقبت بايايان حيات و كيفيت مراقبت تسكينى از نظر خانوادههاى داراى بيماران در حال احتضار انجام شد، نشان داد كيفيت مراقبت دريت
ميانخين نمره در بعد مديريت كاهش علايم 1/9 \

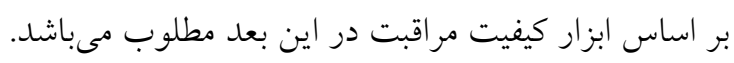

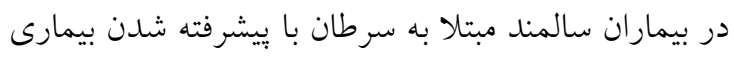

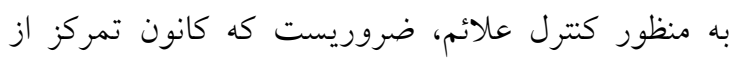
اقدامات درمانى به مراقبت تغيير نمايد، كاهش علاتهرون علايم

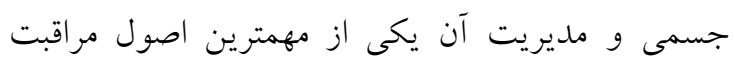

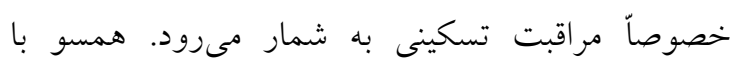

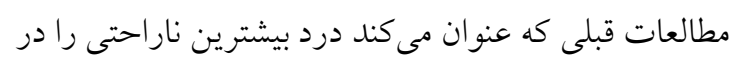

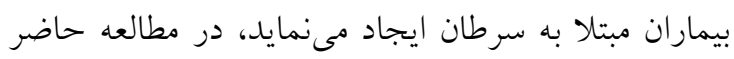

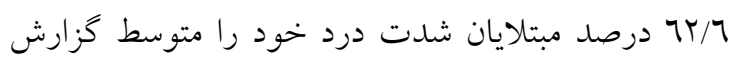

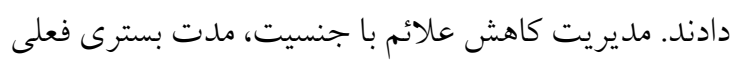

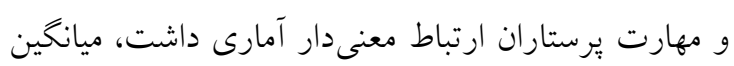

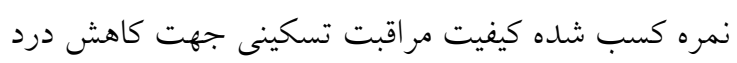

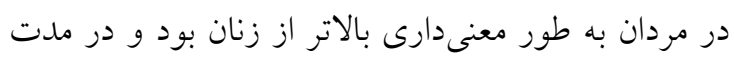

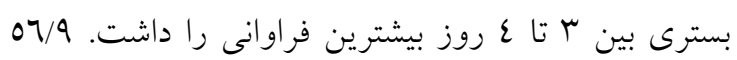
درصد نمونهها سابقه بسترى قبلى داشتند كه بيشتر آنها بين روز بينت فرين

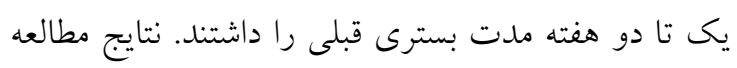

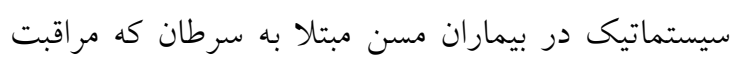
تسكينى دريافت كردند نشان داد بيشترين علايم زجرآور

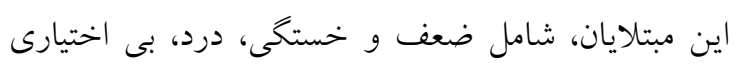

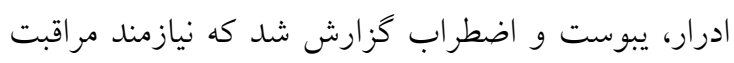
بيشترى در اين زمينه است (10) در اين زمينه نتايج مطالعه حاضر همسو و مطابق با يافته

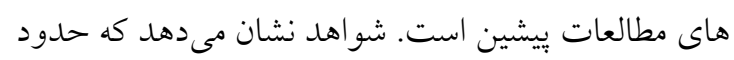

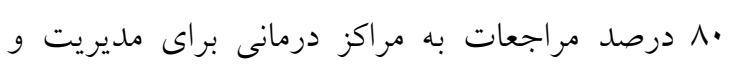

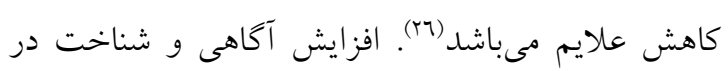
مورد بيمارى، عوارض آن، اطلاعات در زمينه عود و و واند

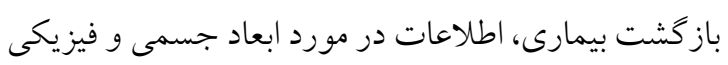

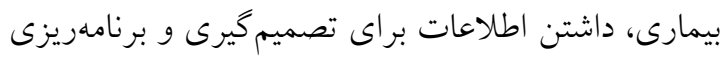

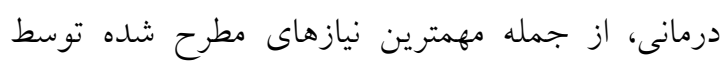
بيماران است و تأييد كننده اين است كه تأمين نيازهاى

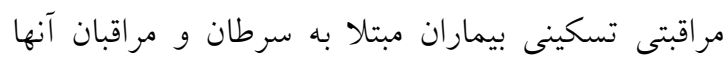

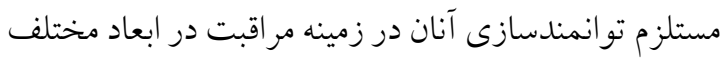
جسمى، روانى، اجتماعى و معنوى است شواهد موجود موند 
دليل بيمارى زندكى خود را در معرض خطر مىبينند، بيشتر

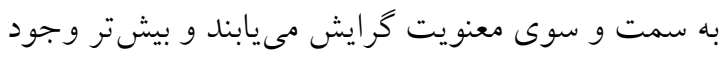

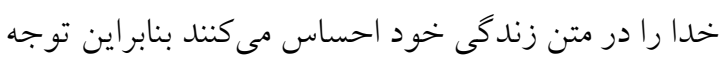

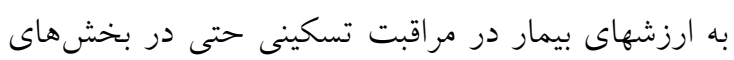

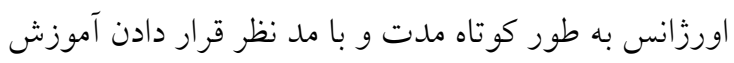

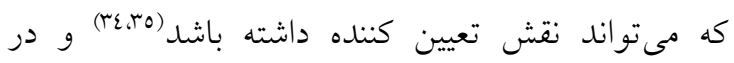
مطالعاتى كه در خصوص بيمارىهاى بيشرفته كبدى و

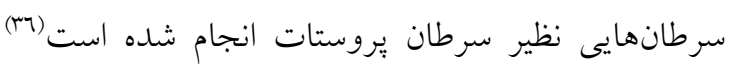

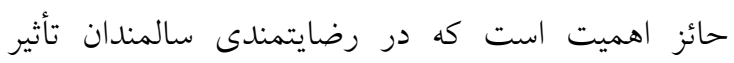

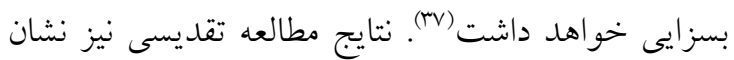
داد از طريق مداخلات آموزشى مؤثر و مبتنى بر برنامههاى بـاي

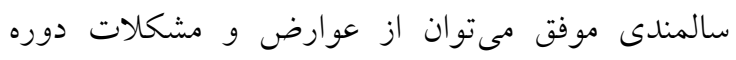

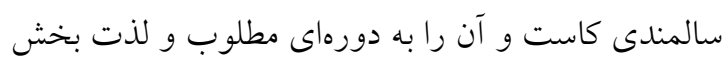
تبديل نمود (r)

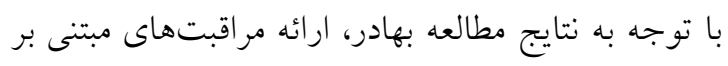

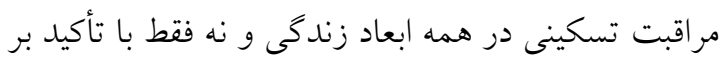

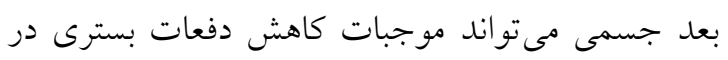

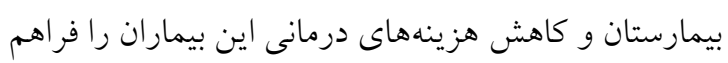

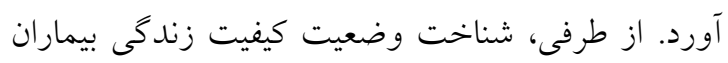

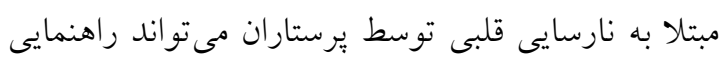

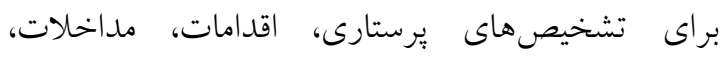

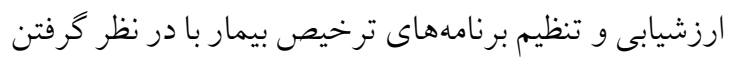

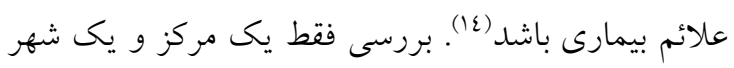

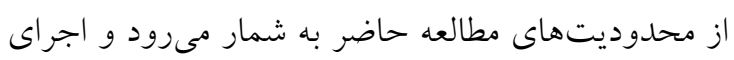
مطالعه در ساير مراكز و شهرها ضرورى است. همجنينين

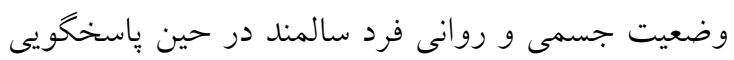
به سؤ الات برسشنامه و احتمال ايجاد خستكى كه بر نحوه

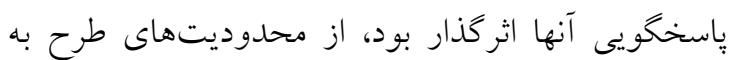

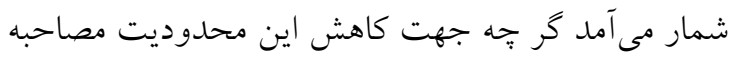

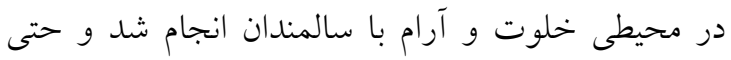
الامكان با دادن زمان استر احت ده دقيقهاى در فواصل زمانى ير سشنامهها تكميل گرديد. در اين مطالعه مراقبت تسكينى از ديدكاه سالمندان مورد

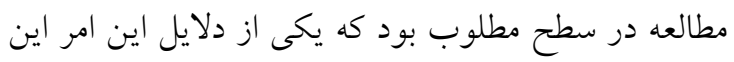

پايان حيات در افراد مبتلا به سرطان و بيمارى زوال عقل خيلى بهتر از بيماران مبتلا به نارسايى كليه بيشرفته و و بئه

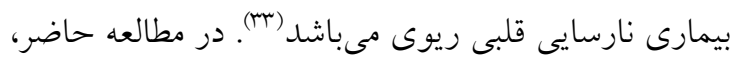

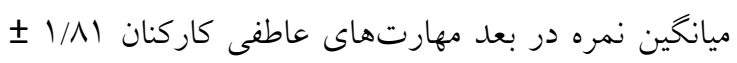

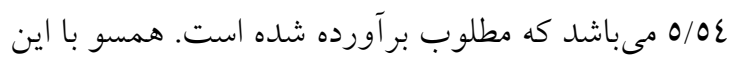

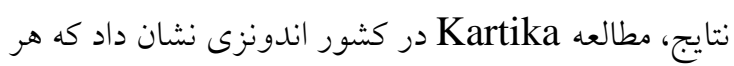
جه ارتباط مطلوبترى بين برستار با بيمار در هنگام

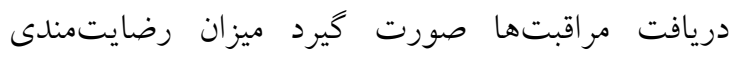

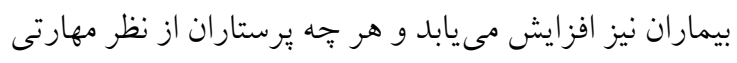
و سابقه حرفهاى با تجربهتر باشند و هنغام ارايه خدمات

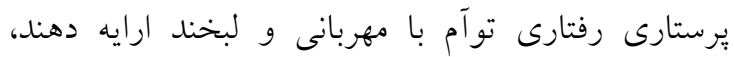

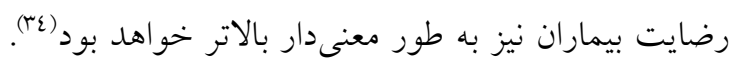

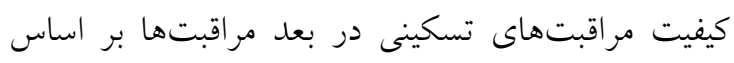

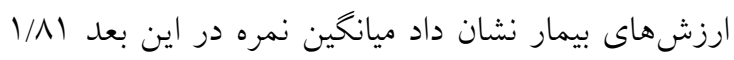

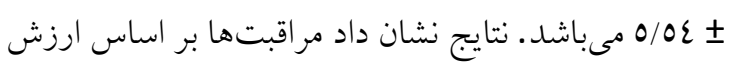
هاى بيمار با مدت بسترى فعلى و مهارت يرستاران ارتباط

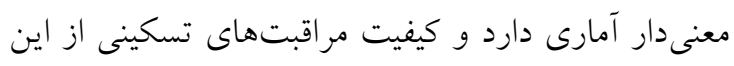

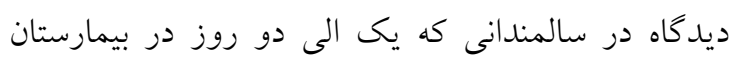
بسترى بودند نسبت به كسانى كه مدت بستريشان بيشتر از

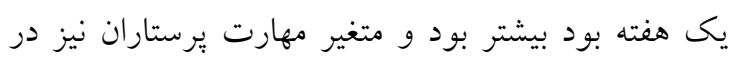

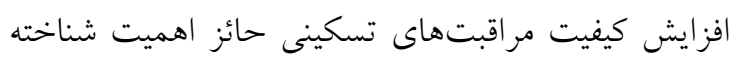
شد. در تأثير مراقبتهاى تسكينى بر كيفيت زندكى افراد

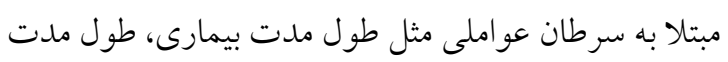

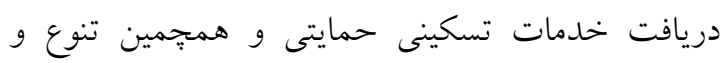
كيفيت اين خدمات مؤثر مىباشد.

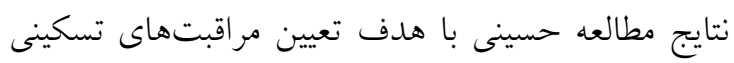

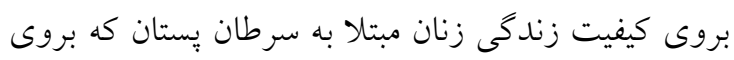

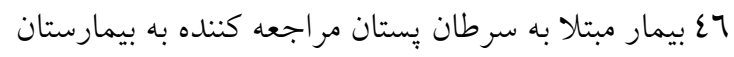

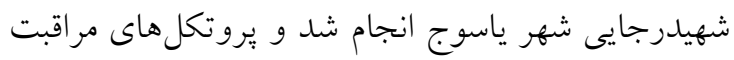

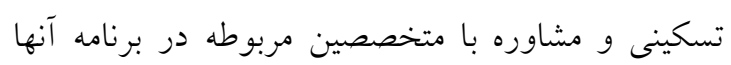

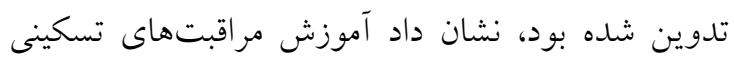

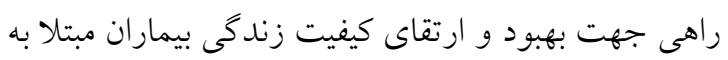

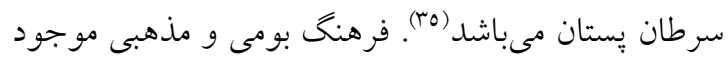

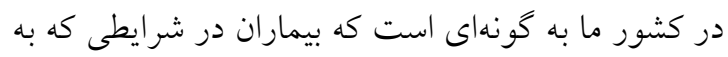




$$
\begin{aligned}
& \text { سالمندان يير يا خيلى بير صورت كيرد. هم جنين توصيه }
\end{aligned}
$$

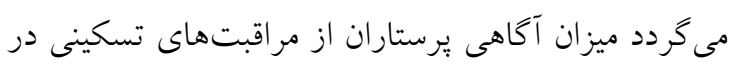

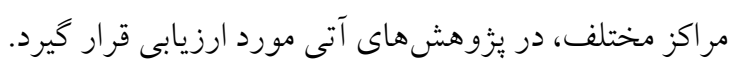

$$
\begin{aligned}
& \text { تعارض منافع: هيج كونه تعارض منافع از سوى } \\
& \text { نويسندكان كزارش نشده است. }
\end{aligned}
$$

\section{تقدير و تشكر}

اين مقاله حاصل طرح تحقيقاتى شماره -3-3-208

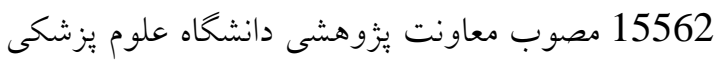

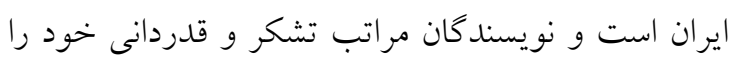

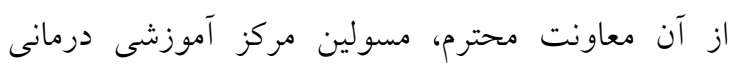

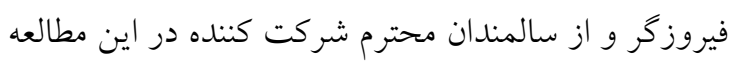

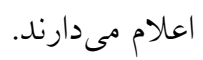

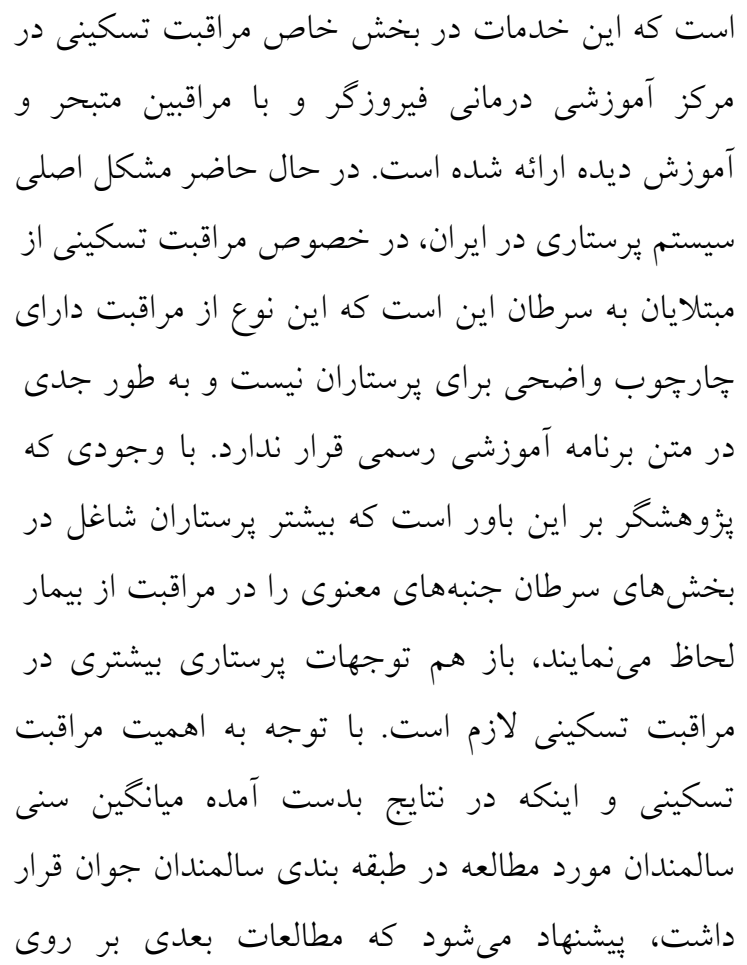

\section{References}

1. World Health Organization. Latest global cancer data: Cancer burden rises to 18.1 million new cases and 9.6 million cancer deaths in 2018. International Agency for Research on Cancer. Geneva: World Health Organization. 2018 Sep 12.

2. Sharifzadeh G, Moodi M, Akhbari H. Investigating health status of older people supported by Imam. Iranian journal of ageing. 2010;5(3):52-9. [Persian]

3. Mirzaei M, Shams Ghahfarokhi M. Demography of elder population in Iran over the period 1956 To 2006. Iranian Journal of Ageing. 2007;2(3):326-31. [Persian]

4. Dilorio CK. Measurement in health behavior: methods for research and evaluation. John Wiley \& Sons; 2006 Mar 6.

5. World Health Organization. Cancer WHO; 2021 [updated 3 March 2021- 2021 August 4]. Available from: https://www.who.int/news-room/fact-sheets/detail/cancer.

6. Weinberger MI, Bruce ML, Roth AJ, Breitbart W, Nelson CJ. Depression and barriers to mental health care in older cancer patients. Int J Geriat Psych. 2011;26(1):21-6.

7. Cinar D, Tas D. Cancer in the elderly. Northern clinics of Istanbul. 2015;2(1):73.

8. De Martel C, Ferlay J, Franceschi S, Vignat J, Bray F, Forman D, Plummer M. Global burden of cancers attributable to infections in 2008: a review and synthetic analysis. The lancet oncology. 2012;13(6):607-15.

9. Barbera L, Paszat L, Charter C. Indicators of poor quality end-of-life cancer care in Ontario. $J$ Palliat Care. 2006;22(1):12-7.

10. Agar M, Currow DC, Shelby-James TM, Plummer J, Sanderson C, Abernethy AP. Preference for place of care and place of death in palliative care: are these different questions?. Palliative medicine. 2008;22(7):787-95.

11. Graphic PC. Dying in America: Improving quality and honoring individual preferences near the end of life. 2014.

12. Twycross RG. Introducing palliative care. Radcliffe Publishing; 2003.

13. World Health Organization. Ageing and health: WHO; 2018 [2020-9-3]. Available from: https://www.who.int/news-room/fact-sheets/detail/ageing-and-health. 
14. Nouhi E, Jahani Y. The study of palliative care and its relationship with quality of life in patients with chronic heart failure. in 2014-2015. Journal of Clinical Nursing and Midwifery. 2017;5(4):3546. [Persian]

15. Kartika IR, Hariyati TS. Nelwati. Nurses-patients interaction model and outpatients' satisfaction on nursing care. Nurse Care Open Acces J. 2018;5(2):70-6.

16. Engelberg RA, Downey L, Wenrich MD, Carline JD, Silvestri GA, Dotolo D, Nielsen EL, Curtis JR. Measuring the quality of end-of-life care. J Pain Symptom Manage. 2010;39(6):951-71.

17. Gholjeh M, Dastoorpour M, Ghasemi A. The relationship between nursing care quality and patients satisfaction among hospitals affiliated to Zahedan University of medical sciences in 2014. Jorjani Biomedicine Journal. 2015;3(1):68-81. [Persian]

18. Nazari B, Bakhshi S, Kaboudi M, Dehghan F, Ziapour A, Montazeri N. A comparison of quality of life, anxiety and depression in children with cancer and healthy children, Kermanshah-Iran. International Journal of Pediatrics. 2017;5(7):5305-14. [Persian]

19. Abdel Maqsood AS, Oweis AI, Hasna FS. Differences between patients' expectations and satisfaction with nursing care in a private hospital in Jordan. Int J Nurs Pract. 2012;18(2):140-6.

20. Al-Awamreh K, Suliman M. Patients' satisfaction with the quality of nursing care in thalassemia units. Appl Nurs Res. 2019;47:46-51.

21. Schroeder K, Lorenz K. Nursing and the future of palliative care. Asia-Pacific J Oncol Nurs. 2018;5(1):4-8

22. Altaker KW, Howie-Esquivel J, Cataldo JK. Relationships among palliative care, ethical climate, empowerment, and moral distress in intensive care unit nurses. Am J Crit Care. 2018;27(4):295302.

23. Arnold EC, Boggs KU. Interpersonal relationships e-book: professional communication skills for nurses. Elsevier Health Sciences; 2019 Feb 2.

24. Evangelista LS, Lombardo D, Malik S, Ballard-Hernandez J, Motie M, Liao S. Examining the effects of an outpatient palliative care consultation on symptom burden, depression, and quality of life in patients with symptomatic heart failure. J Cardiac Failure. 2012;18(12):894-9.

25. Van Lancker A, Velghe A, Van Hecke A, Verbrugghe M, Van Den Noortgate N, Grypdonck M, Verhaeghe S, Bekkering G, Beeckman D. Prevalence of symptoms in older cancer patients receiving palliative care: a systematic review and meta-analysis. $J$ pain symptom manag. 2014;47(1):90-104.

26. Rassouli M, Sajjadi M. Palliative care in the Islamic Republic of Iran. Palliative care to the cancer patient: The Middle East as a model for emerging countries. New York: Nova Scientific Publisher. 2014:39.

27. Ghazimirsaeed SJ, Moghimkhan F. Information Behavior of Patients with Cancer in Palliative Care in Tehran City, Iran. Health Information Management. 2018;15(3):120-5. [Persian]

28. Valizadeh L, Zamanzadeh V, Rahmani A, Howard F, Nikanfar AR, Ferguson C. Cancer disclosure: Experiences of Iranian cancer patients. Nursing \& health sciences. 2012;14(2):250-6.

29. Jacobsen R, Møldrup C, Christrup L, Sjøgren P, Hansen OB. Psychological and behavioural predictors of pain management outcomes in patients with cancer. Scand J Caring Sci. 2010;24(4):781-90.

30. Money S, Garber B. Management of cancer pain. Curr Emerg Hospital Medic Reports. 2018;6(4):141-6.

31. Jones R, Regan M, Ristevski E, Breen S. Patients' perception of communication with clinicians during screening and discussion of cancer supportive care needs. Patient education and counseling. 2011;85(3):e209-15.

32. Ferrell BR, Twaddle ML, Melnick A, Meier DE. National consensus project clinical practice guidelines for quality palliative care guidelines. J Palliat Medic. 2018;21(12):1684-9.

33. Wachterman MW, Pilver C, Smith D, Ersek M, Lipsitz SR, Keating NL. Quality of end-of-life care provided to patients with different serious illnesses. JAMA internal medicine. 2016;176(8):1095102.

34. Kartika IR, Hariyati TS. Nelwati. Nurses-patients interaction model and outpatients' satisfaction on nursing care. Nurse Care Open Acces J. 2018;5(2):70-6.

35. da Silva Soares D, Nunes CM, Gomes B. Effectiveness of emergency department based palliative Care for Adults with advanced disease: a systematic review. J Palliat Medic. 2016;19(6):601-9. 
36. Sanford MT, Greene KL, Carroll PR. The argument for palliative care in prostate cancer. Translational andrology and urology. 2013;2(4):278-80.

37. Huynh L, Moore J. Palliative and end-of-life care for the older adult with cancer. Current Opinion in Supportive and Palliative Care. 2021;15(1):23-8.

38. Taghdisi MH, Doshmangir P, Dehdari T, Doshmangir L. Influencing Factors on Healthy Lifestyle From Viewpoint of Ederly People: Qualitative Study. Iranian Journal of Ageing. 2013;7(4):47-58. [Persian] 